\title{
Increased monocyte actin polymerization in rat blood after intratracheal instillation of air pollution particles
}

\author{
Rachel A. Adams ${ }^{\mathrm{a}, *}$, Ameena Al-Mosawi ${ }^{\mathrm{a}}$, Kelly Bérubé ${ }^{\mathrm{b}}$, Tim Jones ${ }^{\mathrm{c}}$, \\ Timothy Higgins ${ }^{\mathrm{b}}$ and Shelley-Ann Evans ${ }^{\mathrm{a}}$ \\ ${ }^{a}$ Cardiff School of Health Sciences, Cardiff Metropolitan University, Cardiff, UK \\ ${ }^{\mathrm{b}}$ Cardiff School of Biosciences, Cardiff University, Cardiff, UK \\ ${ }^{\mathrm{c}}$ School of Earth and Ocean Sciences, Cardiff University, Cardiff, UK
}

Received 18 July 2014

Accepted in revised form 27 September 2014

\begin{abstract}
.
BACKGROUND: Exposure to particulate air pollution is associated with an increased risk of cardiovascular disease. The mechanism by which exposure increases risk is poorly understood but could involve changes in the flow properties of blood. OBJECTIVE: The aim of this investigation was to assess the effect, in rats, of intratracheal instillation of particulate air pollution on leukocyte flow properties by measurement of polymorphonucleocyte (PMN) and monocyte actin polymerisation. METHODS: Rats were exposed to particulate air pollution by intratracheal instillation of $\mathrm{PM}_{10}$. Blood was collected from test and control animals at 3 days $(n=10)$ and 6 weeks $(n=10)$ after dust instillation. Partial differential leukocyte counts were performed. The intracellular F-actin content of blood PMNs and monocytes was determined by staining with FITC-phalloidin and flow cytometric determination of mean florescence intensity (MFI).

RESULTS: There were no significant changes in PMN MFI $(p=0.369$, ANOVA) or cell counts $(p=0.753$, ANOVA). There was a significant increase in monocyte MFI ( $p=0.004$, ANOVA) and a decrease in monocyte cell count $(p=0.003$, ANOVA) in instilled rats.

CONCLUSIONS: Intratracheal instillation of air pollution particles resulted in an increase in blood monocyte actin polymerisation, which may cause trapping of monocytes. This could be a mechanism by which exposure to air pollution increases the risk of cardiovascular disease.
\end{abstract}

Keywords: Particles, leukocyte, neutrophil, cytoskeleton, cardiovascular disease

\section{Introduction}

Epidemiological studies have shown increased exposure to airborne particulate matter with an aerodynamic diameter of less than 10 microns $\left(\mathrm{PM}_{10}\right)$ increases asthma symptoms, cardiovascular malfunction, hospital admissions and morbidity and mortality rates [1-4]. The American Heart Association

\footnotetext{
${ }^{*}$ Address for correspondence: Dr. Rachel A. Adams, Cardiff School of Health Sciences, Cardiff Metropolitan University, Western Avenue, Cardiff, CF5 2YB, UK. Tel.: +44 29 20416839; Fax: +44 29 20416982; E-mail: RAdams@ cardiffmet.ac.uk.
} 
published an updated statement on air pollution and cardiovascular disease [5] and highlighted research to "improve our understanding of the underlying biological mechanisms" as an important area for future research. Although different reasons have been postulated to link inflammatory changes induced by particle inhalation to such cardiovascular alterations, the causative mechanisms of the cardiovascular insult are, as yet, uncertain. Inflammatory and permeability changes in the lung and epithelial cells after particle exposure have been studied previously [6,7] however, the mechanisms of how these are manifested systemically in the blood are not yet fully understood. Inflammatory changes in peripheral blood have been reported after short term exposure to diesel exhaust fumes in humans [8,9] and after intrapharyngeal instillation of particles in atherosclerotic rats [10]. Incubation with particulates caused inflammatory changes in human alveolar macrophages [11], and in rat alveolar macrophages and human peripheral monocytes [12]. Interestingly particle associated disturbances in microvascular function, in rats, have even been reported in the absence of detectable pulmonary inflammation [13].

Changes in the flow properties of blood, in particular blood cells, are associated with a wide range of diseases including myocardial infarction, stroke and peripheral vascular disease [14-17]. Blood cells must deform to flow through capillaries, as the lumen diameter of the vessel is often smaller than the diameter of the cells themselves. Erythrocytes are well adapted for flow and deform easily during flow. Leukocytes, however, perform a dual role of immune surveillance and response, have a more complex intracellular structure and deform much more slowly than erythrocytes $[18,19]$. Leukocytes interact with the vascular endothelium and a range of external factors increase [20] or decrease [21] the adhesive interaction. Polymorphonucleocytes (PMNs) and monocytes, in particular, may become 'activated' which results in actin polymerization and a significant reduction in cell deformability [22-24]. These poorly deformable leukocytes may become trapped in the microcirculation, increasing peripheral resistance and decreasing blood flow to tissues $[25,26]$.

Some association between exposure to particulate air pollution and changes in blood rheology have been previously reported. Peters et al. [2] found an increase in plasma viscosity with increased exposure to air pollution in man. Our research group has previously reported an increase in plasma viscosity in rats which correlates with the degree of inflammatory changes in the lung after instillation of particles [27]. A decrease in peripheral red blood cell count with increased exposure to $\mathrm{PM}_{10}$ has been reported [28]. The authors suggested that this decrease in red cell count was caused by sequestration of red cells in the microcirculation but offered no mechanistic evidence to support this hypothesis. Khandoga et al. [29] reported that intra-arterial infusion of ultrafine particles resulted in an accumulation of platelets in the hepatic microcirculation of mice, by increased platelet adhesion to the vascular endothelium.

To date few studies on the effect of particulate air pollution on leukocyte rheology have been reported, however, diesel exhaust particle exposure results in changes in the cytoskeletal structure and biophysical properties of aortic endothelial cells [30] and lung epithelial cell [31]. Cigarette smoke is known to be detrimental to blood rheology as exposure to cigarette smoke causes a marked distortion of neutrophil cell shape with bleb formation, and decreased deformability [32], and changes in platelet aggregation [33]. Also, chronic smokers have decreased blood filterability and increased levels of plasma elastase [34]. Cigarette smoke, therefore, causes changes in leukocyte rheology but the effect of particulate air pollution on leukocyte rheology is unclear.

The aim of the study described here was to test the hypothesis that exposure to airborne particulate pollution causes changes in cytoskeletal assembly in blood leukocytes. To this end the effect, in rats, of intratrachaeal instillation of $\mathrm{PM}_{10}$ on F-actin content in blood PMNs and monocytes was measured. 


\section{Materials and methods}

\subsection{Animals and experimental protocol}

All animals were treated humanely under guidelines provided by Cardiff University and the local ethical committee. Study approval was obtained from the local ethical committee and from the UK Home Office. Sample size was chosen on the basis of power calculations to give a greater than $80 \%$ chance of detecting a statistically significant $(p<0.05)$ difference in F-actin concentration between control and test animals. The animal and experimental protocols used were as previously reported [27]. Briefly, male Sprague Dawley rats (200 g, $n=10$ per group) were purchased from Charles River (UK) and were acclimatised within the animal holding facility for one week prior to instillation. The animals were kept on wire-bottom cages with pelleted food and tap water ad libitum. The animals were lightly anaesthetised with Halothane before receiving intratracheal instillations. Dose and time course was chosen on the basis of previous studies on the effects of $\mathrm{PM}_{10}$ instillation [35]. A high dose was chosen to ensure that inflammatory changes occurred in the lung. Controls were instilled with saline only $(0.5 \mathrm{ml})$ whilst test animals were instilled with saline $(0.5 \mathrm{ml})$ containing $2.5 \mathrm{mg} / \mathrm{kg}$ of $\mathrm{PM}_{10}$. Test and control animals were harvested at both three days and six weeks after dust instillation. The six week time point post instillation was chosen to determine systemic effects occurring post resolution of the acute lung inflammatory changes. The free cell population in lung lavage fluid is not significantly raised at six weeks post instillation of diesel exhaust particles [6]. There were no differences in control animal cell counts or mean fluorescence intensity (MFI) between three days and six weeks post instillation.

\subsection{Collection and preparation of $P M_{10}$}

Urban air pollution particles were collected using a high volume impactor (HVI) [36]. The machine is capable of collecting large amounts of sample within a foam substrate. The particles are easily removed from the substrate with minimum sample alteration. The HVI runs on a 40-Amp electrical supply, sucking air at $1100 \mathrm{l} / \mathrm{min}$ through the head containing the foam substrates. There are cylindrical inlets through which the air passes. Air passes through a debris collector, where any particles bigger than $10 \mu \mathrm{m}$ are trapped on a polyurethane foam (PUF) substrate. Particles smaller than $10 \mu \mathrm{m}$ pass through a second cylindrical inlet and impact in a second PUF substrate. The PUF were collected and chopped into small pieces then vigorously agitated with distilled water. The particles were then freeze dried and stored at $4^{\circ} \mathrm{C}$ [36]. A known mass of particles was resuspended in $0.15 \mathrm{M}$ saline and 'wetted' (suspended in solution) by 15 min sonication. Particle physicochemistry was assessed by transmission electron microscopy, X-ray microanalysis, and quantitative image analysis (Table 1). Particles consisted of about $10 \%$ ultrafine particles $(<100 \mathrm{~nm})$.

Table 1

Size distribution and inorganic elemental composition of particles

\begin{tabular}{lcccc}
\hline $\begin{array}{l}\text { Mean diameter } \\
(\mathrm{nm})\end{array}$ & $\begin{array}{c}\text { \% ultrafine } \\
(<100 \mathrm{~nm})\end{array}$ & $\begin{array}{c}\% \text { fine } \\
(0.1-2.5 \mu \mathrm{m})\end{array}$ & $\begin{array}{c}\text { \% coarse } \\
(0.1-2.5 \mu \mathrm{m})\end{array}$ & $\begin{array}{c}\text { Elemental composition } \\
\text { (inorganic) }\end{array}$ \\
\hline 30 & 10.1 & 89.5 & 0.4 & $\mathrm{C}, \mathrm{O}, \mathrm{Na}, \mathrm{Mg}, \mathrm{Al}, \mathrm{Si}, \mathrm{P}, \mathrm{S}, \mathrm{Cl}, \mathrm{K}$, \\
$\mathrm{Ca}, \mathrm{Ti}, \mathrm{Mn}, \mathrm{Cr}, \mathrm{Fe}, \mathrm{Zn}, \mathrm{Pb}$
\end{tabular}




\subsection{Blood samples and cell counting}

Blood samples were collected, by cardiac puncture, into sufficient tri-potassium EDTA to give a final concentration of $1.5 \mathrm{mg} / \mathrm{ml}$. Three part differential leukocyte counts were performed using a SeronoBaker System 9000 automated cell counter (Bio-Stat Diagnostic Systems, Stockport, Cheshire, UK) to count lymphocytes, PMNs and "mid-range" cells. Mid-range cells consisted of 80\% monocytes [19]. A sample of cells were fixed immediately for measurement of F-actin content. The total free cell number present in lung lavage fluid, a measure of lung damage, was measured as previously described [6].

\subsection{Flow cytometric determination of F-actin in PMNs and monocytes}

Red cells were lysed, and leukocytes were partially fixed and permeabilized using a cell permeabilization kit (Harlan SERA-LAB Ltd, Loughborough, UK). Intracellular F-actin was stained by incubation of cells with fluorescein isothiocyanate (FITC)-phalloidin $\left(1.6 \times 10^{-6} \mathrm{M}\right)$ (Molecular Probes, F432) and mean fluorescence intensity was measured by flow cytometry using a Beckton Dickinson FACScan (Becton Dickinson UK Ltd, Between Towns Road, Oxford, UK).

Using a combination of forward angle light scatter (FSC) and side angle light scatter (SSC), lymphocytes, remaining red cells and cell debris were excluded from analysis by appropriate gating of PMNs and monocytes. Gates were adjusted so that the percentage of cells identified for each cell type were identical to those identified in cell counts performed using a Serono-Baker System 9000 automated cell counter (Bio-Stat Diagnostic Systems, Stockport, Cheshire, UK). In addition anti-rat PMN and anti-rat monocyte antibodies were used to confirm the cell type of gated cells. Firstly, R-phycoerythrin (R-PE) anti-rat granulocyte monoclonal antibody was used in fluorescence channel 2, FL2, with R-PE monoclonal immunoglobulin isotype standard $(0.4 \mu \mathrm{g} / \mathrm{l})$ as a control (Becton Dickinson, San Jose, CA, USA). Secondly, biotin anti-rat mononuclear phagocyte was used with biotin mouse IgG1 monoclonal immunoglobulin isotype standard as a control (Becton Dickinson, San Jose, CA, USA). Cocktails containing three labels were added to the whole blood after fixation and along with the permeabilzation step. The biotin labelling method also required streptavidin-peridinin chlorophyll-a protein (PerCP) $(0.1 \mu \mathrm{g} / \mathrm{l})$ (Becton Dickinson, San Jose, CA, USA). The PerCP fluorochrome was added after performing the last wash and was incubated for a further 30 minutes in the dark. After incubation another wash step was performed and cells were re-suspended with $0.5 \mathrm{ml}$ PBS before flow cytometric analysis. Two sets of Isotype controls were prepared to contain FITC and PE and FITC and Biotin. In addition, a suspension of unstained cells was run through the flow cytometer. Electronic compensation was used to correct for spectral overlap and fluorescence gain and photomultiplier voltage were identical for all samples. F-actin content was expressed as MFI.

\subsection{Statistical analysis}

All statistical analysis was performed using Minitab 12 software (Minitab Ltd, Coventry, UK). Values are quoted as mean \pm SEM. Differences between the treatment group and control groups were analysed by one way analysis of variance (ANOVA) where appropriate.

\section{Results}

The dot plot obtained for whole blood lysed, permeabilized and stained with FITC-phalloidin is presented in Fig. 1A. Rat cells were located in regions similar to those for human blood. A minor sub- 
A

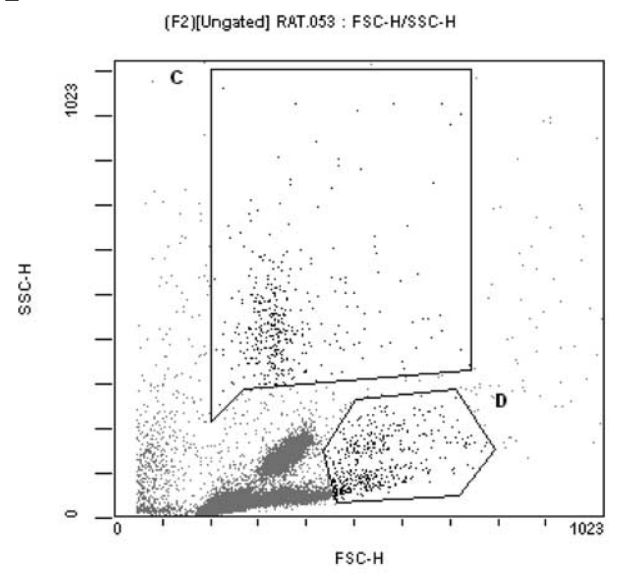

B

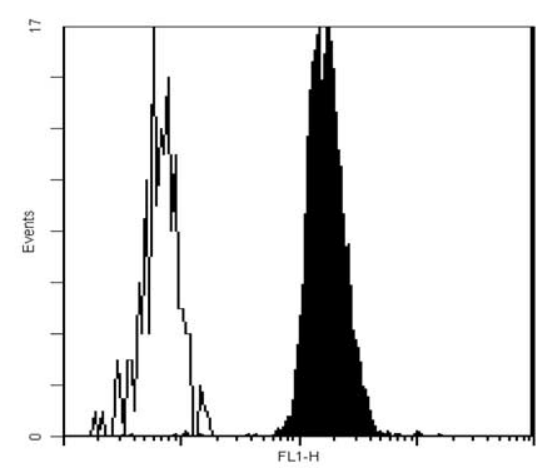

C

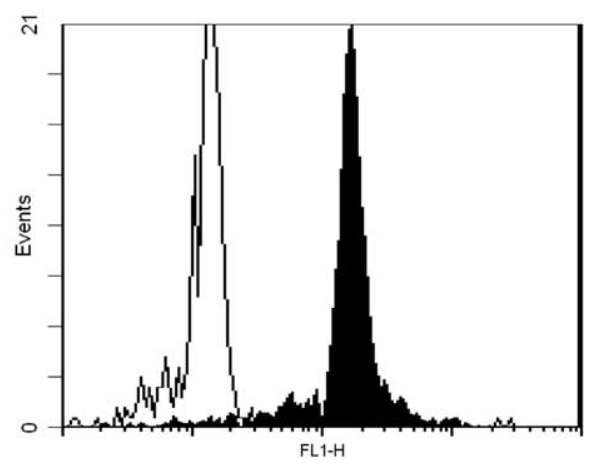

Fig. 1. Flow cytometric analysis of rat PMN and monocytes in whole blood. (A) The FSC/SSC profile for whole rat blood after lysis, permeabilization and staining. PMNs are gated in region $\mathrm{C}$ and monocytes in region D. (B) Histogram of log FL-1 against events for PMNs, gated in C. Cells were stained with FITC-phalloidin (ם) or unstained ( $\square$ ). (C) Histogram of log FL-1 against events for monocytes, gated in D. Cells were stained with FITC-phalloidin (ם) or unstained ( $\square$ ).

population of cells with high SSC, highly granular, was identified. When gated the number of cells in this population was similar to the percentage of cells identified as granulocytes in cell counting with the Serono-Baker 9000 cell counter. A subpopulation of cells with a high FSC-height, large size, and low granularity, were identified. These cells stained positively when incubated with anti-rat PMN antibody. When gated the percentage of cells in this population was similar to the percentage of leukocytes identified as mid range cells with the Serono-Baker 9000 cell counter.

A histogram of $\log$ fluorescence intensity (log FL-1) against events for cells gated in region $\mathrm{C}$ is presented as Fig. 1B. A single peak was identified suggesting a homogeneous cell population. The cells identified are a single population of granular cells with little contamination of lymphocytes as these cells have a low concentration of F-actin and would be recorded as cells with a low fluorescence intensity. A histogram of log FL-1 against events for cells gated in region D is presented in Fig. 1C. A single peak is again identified, again suggesting a homogeneous cell population. The cells identified are a single population with little contamination from lymphocytes as these cells have a low concentration of F-actin 
and would be recorded as cells with a low fluorescence intensity. In both histograms, Fig. 1B and 1C, the unstained cells have a very low fluorescence intensity compared to cells stained, with FITC labelled phalloidin, so the fluorescence recorded in the stained cells is not background or auto fluorescence.

The effect of intratracheal instillation of $\mathrm{PM}_{10}$ on flow cytometric determination of F-actin in blood PMNs and monocytes is summarised in Fig. 2. In monocytes instillation of $\mathrm{PM}_{10}$ resulted in an increase of MFI from $403 \pm 41$ (mean \pm SEM) to $606 \pm 67$ at 3 days post instillation and to $484 \pm 38$ at 6 weeks post instillation. These changes were statistically significant $(p=0.004)$ as determined by one-way analysis of variance. In PMNs instillation of PM $_{10}$ resulted in no change in MFI. The MFI was $343 \pm 40$ for controls, $399 \pm 25$ at 3 days post instillation and $343 \pm 34$ at 6 weeks post instillation. Any changes in MFI in PMNs were not statistically significant $(p=0.369)$ as determined by one-way analysis of variance.

The effect of intratracheal instillation of $\mathrm{PM}_{10}$ on cell counts of blood mid-range cells and granulocytes, counted using an automated cell counter is summarised in Fig. 3. Instillation of $\mathrm{PM}_{10}$ resulted in a decrease in the blood mid range cells from $(0.193 \pm 0.008) \times 10^{6}$ cells $/ \mathrm{ml}$ to $(0.150 \pm 0.008) \times 10^{6} \mathrm{cells} / \mathrm{ml}$ at 3 days post instillation and to $(0.149 \pm 0.009) \times 10^{6}$ cells $/ \mathrm{ml}$ at 6 weeks post instillation. These changes were statistically significant $(p=0.003)$ as determined by one-way analysis of variance. Instillation of $\mathrm{PM}_{10}$ resulted in no change in blood PMN count. The counts were $(0.060 \pm 0.010) \times 10^{6} \mathrm{cells} / \mathrm{ml}$ in controls and $(0.057 \pm 0.006) \times 10^{6}$ cells $/ \mathrm{ml}$ at 3 days post instillation and $(0.069 \pm 0.009) \times 10^{6} \mathrm{cells} / \mathrm{ml}$

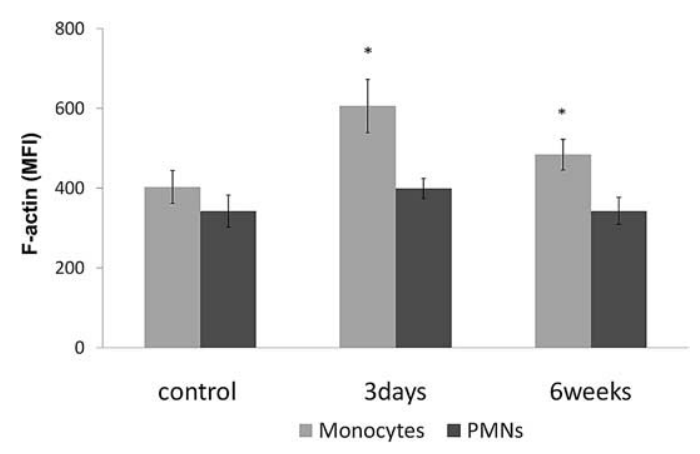

Fig. 2. Effect of intratracheal instillation of $\mathrm{PM}_{10}$ on flow cytometric determination of F-actin (MFI) in blood. Results for monocytes $(p=0.004)$ and PMNs $(p=0.369)$. MFI measured 3 days and 6 weeks post instillation. $p$-values determined by ANOVA; ${ }^{*} p \leqslant 0.05 ; n=8-10$.

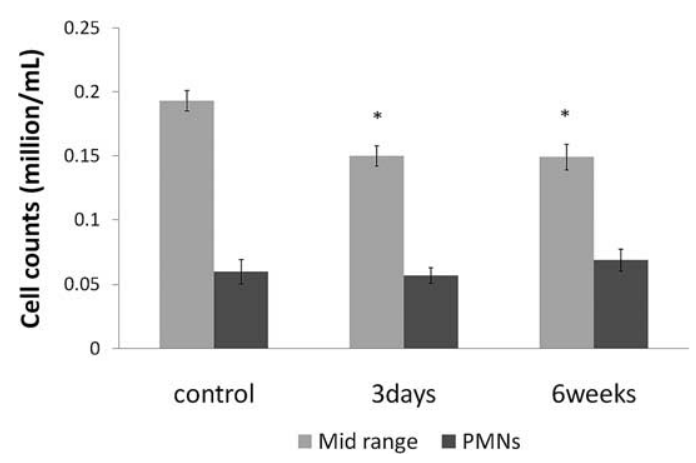

Fig. 3. Effect of intratracheal instillation of $\mathrm{PM}_{10}$ on blood cell counts. Results for blood mid range $(p=0.003)$ and PMNs $(p=0.753)$. Cell counts measured 3 days and 6 weeks post instillation. $p$-values determined by ANOVA; ${ }^{*} p \leqslant 0.05 ; n=8-10$. 
at 6 weeks post instillation. Any changes were not statistically significant $(p=0.753)$ as determined by one-way analysis of variance.

The free cell population in the lung, a marker of lung inflammation, was $(5.5 \pm 0.9) \times 10^{6}$ cells in controls and $(7.4 \pm 0.6) \times 10^{6}$ cells at 1 week post instillation and returned to $(4.0 \pm 0.5) \times 10^{6}$ at 6 weeks post instillation of $\mathrm{PM}_{10}$. Intratracheal instillation of $\mathrm{PM}_{10}$ resulted in no statistically significant changes in lymphocyte count. Lymphocyte counts were $(6.29 \pm 0.47) \times 10^{6}$ cells $/ \mathrm{ml}$ in controls and $(5.822 \pm 0.47) \times 10^{6}$ cells $/ \mathrm{ml}$ at 3 days post instillation and $(5.397 \pm 0.45) \times 10^{6}$ cells $/ \mathrm{ml}$ at 6 weeks post instillation with $p=0.406$ determined by one way analysis of variance.

\section{Discussion}

Intracellular F-actin concentration, in rat PMNs and monocytes, can be determined using a whole blood method for staining with FITC-phalloidin and flow cytometric determination of the MFI. The method involves simultaneous red cell lysis and partial fixation and permeabilization of leukocytes. Isolation of leukocytes or leukocyte subpopulations is not necessary. This is particularly important in analysis of rat PMNs and monocytes as the low concentration of PMNs and monocytes in blood makes isolation of pure cell populations difficult. This study has demonstrated that flow cytometry may be used to determine the MFI of the low number of PMNs and monocytes present in whole rat blood. This is possible as the cells, although present in low numbers appear as distinct populations of cells in plots of SSC and FSC height.

There was no statistically significant change in intracellular F-actin or change in peripheral granulocyte count in rats after intratracheal instillation of $\mathrm{PM}_{10}$. Any changes in F-actin and cell count were small and did not reach statistical significance. Changes in the rheological properties of PMNs may contribute to the increased risk of myocardial infarction associated with exposure to air pollution but data presented here suggests that PMN changes are unlikely to be a major cause of increased risk.

Intratracheal instillation of $\mathrm{PM}_{10}$ in rats resulted in a significant increase in intracellular F-actin concentration and a decrease in the number, of monocytes present in the macrocirculation. Leukocytes with increased intracellular F-actin concentration are less deformable than cells with low F-actin concentration [37]. Monocytes must deform to flow through the microcirculation where the diameter of the capillary lumen is often less that the diameter of the cell. A decrease in deformability will result in an increased resistance to flow, and could cause trapping of the monocyte in the microcirculation [37,38]. Trapping of monocytes in the microcirculation may result in a decrease in the concentration of monocytes in the blood present in the macrocirculation and trapping may, therefore, be assessed by measurement of monocyte concentration in the macrocirculation. A decrease in the concentration of monocytes in blood in the macrocirculation was demonstrated here. Intratracheal instillation of $\mathrm{PM}_{10}$, therefore, resulted in actin polymerization in monocytes and may have caused trapping of the monocytes in the microcirculation.

In some other instillation studies an inflammation associated increase in white cell count has been reported. For example instillation of 3 or 8 doses of $\mathrm{PM}_{10}$ results in significant lung and systemic inflammation and is associated with small increases in systemic leukocytes rather than any reduction [39]. The authors report an almost doubling in the number of lung macrophages after instillation but no statistically significant change in the number of lung PMNs. Despite the extensive inflammatory changes seen in these animals only minor increases in systemic total leukocyte and PMN counts (reaching statistical significance at only the one week timepoint) were reported. No information on the systemic monocyte counts was reported in that study. Here we demonstrate that particle instillation is associated 
with cytoskeletal assembly in leukocytes, and in monocytes in particular. We hypothesise that this actin polymerization is associated with a decrease in systemic monocyte count as the rigid monocytes become trapped in the tissues. This could be confirmed by examination of the tissues of instilled animals using histological methods or intravital microscopy.

The changes in the properties of monocytes associated with $\mathrm{PM}_{10}$ instillation could cause increased cardiovascular risk by both rheological and inflammatory mechanisms. Firstly the rheological mechanisms proposed are as follows. Changes in monocyte cytoskeletal assembly could increase the resistance of flow through the microcirculation and reduce flow of red blood cells through the capillaries and thus reduce oxygen delivery to the tissues. Increased cardiac output is required to maintain blood flow and this could result in atherosclerotic plaque rupture which precipitates myocardial infarction. Over the longer term increased flow resistance could increase damage to the vascular endothelium which would contribute to the development and progression of atherosclerosis. Secondly the inflammatory mechanisms proposed are as follows. The measured changes in monocyte F-actin concentration could indicate an inflammatory response to particulate instillation and activation of monocytes. Polymerization of actin occurs when monocytes are activated [23] and the increase in F-actin measured here could be an indication of generalised activation of monocytes. The actin cytoskeleton is also involved in flow sensing and transduction of signals to adhesion plaques [40,41]. Any changes in cytoskeletal assembly may not only result in changes in the physical properties of cells but also in changes in signalling to other cells. Activation of monocytes results in a number of biochemical changes including production of free radicals, proteolytic enzymes and cytokines and increased adhesion to the vascular endothelium [4248]. Monocyte activation contributes to the development and progression of atherosclerosis and may be important in plaque rupture which precipitates myocardial infarction. It is likely that a combination of both rheological and inflammatory mechanisms explain the increased cardiovascular risk associated with particulate air pollution.

The hypothesised trapping of monocytes reported here is similar to the pollution induced decrease in peripheral red blood cell count reported [28] and to the accumulation of platelets in the microcirculation of mice [29]. Trapping of red cells and platelets in the microcirculation will have a substantial effect on flow in the microcirculation but trapped monocytes may exert an even greater effect. The monocyte concentration in peripheral blood is orders of magnitude lower than that of red cells or platelets. Monocytes, therefore, have little effect on whole blood rheology and flow in the large vessels of the macrocirculation. Monocytes are, however, much larger than and deform much more slowly than red blood cells and platelets when flowing through capillary sized vessels. For example in flow through $5 \mu \mathrm{m}$ capillaries monocytes flow 10,000 times more slowly than red blood cells [49] and monocytes contribute nearly half of the total resistance to flow of blood through synthetic models of the microcirculation [19]. Activated monocytes with increased F-actin concentration will deform even more slowly and have an even greater effect on flow in the microcirculation.

Alternative mechanisms for the decrease in mid-range cell counts reported here could be changes in haematopoiesis or changes in release of mature monocytes from the bone marrow. However, there is no evidence of a generalised haematopoietic change as there was no change seen in lymphocyte count throughout the study. Instillation could also cause inflammatory associated changes in the circulatory half-life of monocytes. Particles could cause generalised systemic inflammation and increased levels of inflammatory biomarkers. No such measures were made in the current study but previous work [39] indicates that IL6 increases immediately post particle exposure but returns to baseline three weeks post exposure. The decrease in mid-range cells could, therefore, be caused either by changes in production or turnover of the cells studied. 
In summary, exposure to $\mathrm{PM}_{10}$ results in activation of blood monocytes. Activation increases actin polymerization which may cause trapping of monocytes in the microcirculation. Trapping of activated monocytes could result in inflammatory changes to the endothelium, reduced blood flow and atherosclerosis. We, therefore, propose a mechanism by which exposure to particulate air pollution increases cardiovascular risk.

\section{References}

[1] Miller KA, Siscovick DS, Sheppard L, Shepherd K, Sullivan JH, Anderson GL, et al. Long-term exposure to air pollution and incidence of cardiovascular events in women. N Eng J Med. 2007;356:447-58.

[2] Peters A, Doring A, Wichmann HE, Koenig W. Increased plasma viscosity during an air pollution episode: a link to mortality? Lancet. 1997;349:1582-7.

[3] Pope CA, III, Burnett RT, Thurston GD, Thun MJ, Calle EE, Krewski D, et al. Cardiovascular mortality and long-term exposure to particulate air pollution: epidemiological evidence of general pathophysiological pathways of disease. Circulation. 2004;109:71-7.

[4] Mannucci PM. Airborne pollution and cardiovascular disease: burden and causes of an epidemic. Eur Heart J. 2013;34:1251-3.

[5] Brook RD, Rajagopalan S, Pope CA III, Brook JR, Bhatnagar A, Diez-Roux AV, et al. Particulate matter air pollution and cardiovascular disease: an update to the scientific statement from the American Heart Association. Circulation. 2010;121:2331-78.

[6] Murphy SA, BeruBe KA, Pooley FD, Richards RJ. The response of lung epithelium to well characterised fine particles. Life Sci. 1998;62:1789-99.

[7] Housley DG, Berube KA, Jones TP, Anderson S, Pooley FD, Richards RJ. Pulmonary epithelial response in the rat lung to instilled Montserrat respirable dusts and their major mineral components. Occup Environ Med. 2002;59:466-72.

[8] Salvi S, Blomberg A, Rudell B, Kelly F, Sandstrom T, Holgate ST, et al. Acute inflammatory responses in the airways and peripheral blood after short-term exposure to diesel exhaust in healthy human volunteers. Am J Resp Crit Care Med. 1999;159:702-9.

[9] Delfino RJ, Staimer N, Thomas T, Polidori A, Arhami M, Gillen DL, et al. Circulation biomarkers of inflammation, antioxidant activity, and platelet activation are associated with primary combustion aerosols in subjects with coronary artery disease. Environ Health Perspect. 2008;116:898-906.

[10] Goto Y, Hogg JC, Shih CH, Ishii H, Vincent R, van Eeden SF. Exposure to ambient particles accelerates monocyte release from bone marrow in atherosclerotic rabbits. Am J Physiol - Lung Cell Mol Physiol. 2004;287:L79-85.

[11] van Eeden SF, Tan WC, Suwa T, Mukae H, Terashima T, Fujii T, et al. Cytokines involved in the systemic inflammatory response induced by exposure to particulate matter air pollutants (PM(10)). Am J Resp Crit Care Med. 2001;164:826-30.

[12] Brown DM, Donaldson K, Borm PJ, Schins RP, Dehnhardt M, Gilmour P, et al. Calcium and ROS-mediated activation of transcription factors and TNF-alpha cytokine gene expression in macrophages exposed to ultrafine particles. Am J Physiol - Lung Cell Mol Physiol. 2004;286:L344-53.

[13] Nurkiewicz TR, Porter DW, Barger M, Castranova V, Boegehold MA. Particulate matter exposure impairs systemic microvascular endothelium-dependent dilation. Environ Health Perspect. 2004;112:1299-306.

[14] Cook AM, Evans SA, Lane IF, Jones JG. Leucocyte filterability: comparing diluted with undiluted blood. Br J Haematol. 1998;102:952-6.

[15] Woodward M, Rumley A, Tunstall-Pedoe H, Lowe GD. Does sticky blood predict a sticky end? Associations of blood viscosity, haematocrit and fibrinogen with mortality in the West of Scotland. Br J Haematol. 2003;122:645-50.

[16] Yarnell JW, Patterson CC, Sweetnam PM, Lowe GD. Haemostatic/inflammatory markers predict 10-year risk of IHD at least as well as lipids: the Caerphilly collaborative studies. Eur Heart J. 2004;25:1049-56.

[17] Toth A, Papp J, Rabai M, Kenyeres P, Marton Z, Kesmarky G, et al. The role of hemorheological factors in cardiovascular medicine. Clin Hemorheol Microcirc. 2014;56:197-204.

[18] Evans SA. Leucocyte filterability: comparing diluted blood with purified cell suspensions. Br J Haematol. 1996;93:295-8.

[19] Jones JG, Adams RA, Cook AM, Evans SA. Examination of a rheological profile for blood using micropore filters. Br J Haematol. 1999;104:100-7.

[20] Hughes SF, Cotter MJ, Evans SA, Jones KP, Adams RA. Role of leucocytes in damage to the vascular endothelium during ischaemia-reperfusion injury. Br J Biomed Sci. 2006;63:166-70.

[21] Vachharajani V, Wang SW, Mishra N, El Gazzar M, Yoza B, McCall C. Curcumin modulates leukocyte and platelet adhesion in murine sepsis. Microcirculation. 2010;17:407-16. 
[22] Kirkpatrick UJ, Adams RA, Lardi A, McCollum CN. Rheological properties and function of blood cells in stored bank blood and salvaged blood. Br J Haematol. 1998;101:364-8.

[23] Singh N, Webb R, Adams R, Evans SA, Al-Mosawi A, Evans M, et al. The PPAR-gamma activator, Rosiglitazone, inhibits actin polymerisation in monocytes: involvement of Akt and intracellular calcium. Biochem Bioph Res Commun. 2005;333:455-62.

[24] Adams RA, Evans SA, Kooshesh F, Jones JG. The effects of temperature on the filtration of diluted blood through $3 \mu \mathrm{m}$ and $5 \mu \mathrm{m}$ filters. Biorheology. 1995;32:643-53.

[25] Lipowsky HH. Microvascular rheology and hemodynamics. Microcirculation. 2005;12:5-15.

[26] Lipowsky HH. In vivo studies of blood rheology in the microcirculation in an in vitro world: past, present and future. Biorheology. 2013;50:3-16.

[27] Evans SA, Al-Mosawi A, Adams RA, Berube KA. Inflammation, edema, and peripheral blood changes in lung-compromised rats after instillation with combustion-derived and manufactured nanoparticles. Exp Lung Res. 2006;32:363-78.

[28] Seaton A, Soutar A, Crawford V, Elton R, McNerlan S, Cherrie J, et al. Particulate air pollution and the blood. Thorax. 1999;54:1027-32.

[29] Khandoga A, Stampfl A, Takenaka S, Schulz H, Radykewicz R, Kreyling W, et al. Ultrafine particles exert prothrombotic but not inflammatory effects on the hepatic microcirculation in healthy mice in vivo. Circulation. 2004;109:1320-5.

[30] Wu Y, Yu T, Gilbertson TA, Zhou A, Xu H, Nguyen KT. Biophysical assessment of single cell cytotoxicity: diesel exhaust particle-treated human aortic endothelial cells. PLoS One. 2012;7:e36885.

[31] Wu Y, McEwen GD, Tang M, Yu T, Dimmick JT, Zhou A, et al. Sensing biophysical alterations of human lung epithelial cells (A549) in the context of toxicity effects of diesel exhaust particles. Cell Biochem Biophys. 2013;67:1147-56.

[32] Buttrum SM, Drost EM, MacNee W, Goffin E, Lockwood CM, Hatton R, et al. Rheological response of neutrophils to different types of stimulation. J Appl Physiol. 1994;77:1801-10.

[33] Lardi E, Ott C, Schulzki T, Kuhn M, Bonetti PO, Reinhart WH. Acute effects of short-term exposure to second-hand smoke on induced platelet aggregation. Clin Hemorheol Microcirc. 2010;45:359-64.

[34] Drost EM, Selby C, Bridgeman MM, MacNee W. Decreased leukocyte deformability after acute cigarette smoking in humans. Am Rev Respir Dis. 1993;148:1277-83.

[35] Wise H, Balharry D, Reynolds LJ, Sexton K, Richards RJ. Conventional and toxicogenomic assessment of the acute pulmonary damage induced by the instillation of Cardiff PM10 into the rat lung. Sci Total Environ. 2006;360:60-7.

[36] Greenwell LL, Jones TP, Richards RJ. The collection of PM10 for toxicological investigation: comparisons between different collecting devices. Environ Monit Assess. 2002;79:251-73.

[37] Harris AG, Skalak TC. Leukocyte cytoskeletal structure determines capillary plugging and network resistance. Am J Physiol - Heart Circ Physiol. 1993;265:H1670-5.

[38] Helmke BP, Bremner SN, Zweifach BW, Skalak R, Schmid-Schönbein GW. Mechanisms for increased blood flow resistance due to leukocytes. Am J Physiol - Heart Circ Physiol. 1997;42:H2884-90.

[39] Tamagawa E, Bai N, Morimoto K, Gray C, Mui T, Yatera K, et al. Particulate matter exposure induces persistent lung inflammation and endothelial dysfunction. Am J Physiol - Lung Cell Mol Physiol. 2008;295:L79-85.

[40] Rahimzadeh J, Meng F, Sachs F, Wang J, Verma D, Hua SZ. Real-time observation of flow induced cytoskeletal stress in living cells. Am J Physiol - Cell Physiol. 2011;301:C646-52.

[41] Dahl KN, Kalinowski A, Pekkan K. Mechanobiology and the microcirculation: cellular, nuclear and fluid mechanics. Microcirculation. 2010;17:179-91.

[42] Blann AD, Adams R, Ashleigh R, Naser S, Kirkpatrick U, McCollum CN. Changes in endothelial, leucocyte and platelet markers following contrast medium injection during angiography in patients with peripheral artery disease. Br $\mathrm{J}$ Radiol. 2001;74:811-7.

[43] Blann AD, Seigneur M, Adams RA, McCollum CN. Neutrophil elastase, von Willebrand factor, soluble thrombomodulin and percutaneous oxygen in peripheral atherosclerosis. Eur J Vasc Endovasc Surg. 1996;12:218-22.

[44] Kirkpatrick UJ, Blann AD, Adams RA, McCollum CN. Soluble adhesion molecules in clinical ischaemic injury. Int J Surg Investig. 2000;2:151-8.

[45] Richard S, Seigneur M, Blann A, Adams R, Renard M, Puntous M, et al. Vascular endothelial lesion in patients undergoing bone marrow transplantation. Bone Marrow Transplant. 1996;18:955-9.

[46] Alhejily W, Aleksi A, Martin BJ, Anderson TJ. The effect of ischemia-reperfusion injury on measures of vascular function. Clin Hemorheol Microcirc. 2014;56:265-71.

[47] Chen Z, Zhang X, Deng X. Swirling flow can suppress monocyte adhesion in the flow disturbance zones of the endovascular stent. Biorheology. 2012;49:341-52.

[48] Watts T, Barigou M, Nash GB. Comparative rheology of the adhesion of platelets and leukocytes from flowing blood: why are platelets so small? Am J Physiol - Heart Circ Physiol. 2013;304:H1483-94.

[49] Adams RA, Evans SA, Jones JG. Characterization of leukocytes by filtration of diluted blood. Biorheology. 1994;31:60315. 